\title{
Benefits of Field Modelling for Smoke Control Assessment in Large Volume
}

\author{
FRANÇOIS DEMOUGE, and PHILIPPE FROMY \\ DSSF/ISTA/Pôle Feu \\ CSTB \\ 84, avenue Jean Jaurès - Champs sur Marne - BP 02 \\ F-77421 Marne-la-Vallée Cedex 2
}

ABSTRACT

The aim of this paper is to present a comparison of results obtained with several fire models on an application of smoke control system design for a large volume within the new French regulation framework. Three fire models are used: a simple hot layer model, a 2-zone model (FISBA) and a field model (FDS). The large volume used as a sample is $5000 \mathrm{~m}^{2}$ of floor area and $19 \mathrm{~m}$ high. Three different exhaust configurations are studied for one single 5 MW fire scenario. Results show a good agreement between models for no or low exhaust flow rate while discrepancy increases for high exhaust flow rate. Discrepancy, which affects smoke control system design and fire safety analysis, is mainly explained by the strong fluid movements that are predicted with field modelling. Further research is need in order to determine which model is better adapted to a specific situation with regards to building volume dimensions, fire heat release rate and exhaust rate.

KEYWORDS: fire safety engineering, smoke control, large volume, modelling tools comparison

\section{NOMENCLATURE}

$\begin{array}{llll}C_{P} & \text { specific heat at constant pressure } & \dot{Q}_{e x} & \text { heat loss by exhaust fans } \\ C_{V} & \text { specific heat at constant volume } & t & \text { time } \\ e_{L} & \text { smoke layer thickness } & T & \text { local temperature } \\ g & \text { gravity acceleration } & T_{a} & \text { ambient temperature } \\ h & \text { convective heat transfer coefficient } & T_{b} & \text { lower layer average temperature } \\ H & \text { ceiling height } & T_{L} & \text { smoke layer average temperature } \\ H_{L} & \text { smoke layer height } & S_{c e i l i n g} & \text { ceiling area } \\ w & \text { building volume width } & \dot{V}_{e x} & \text { exhaust volume flow rate } \\ L & \text { building volume length } & V_{L} & \text { smoke layer volume } \\ \dot{m}_{P} & \text { plume mass flow rate } & z & \text { height above floor } \\ \dot{m}_{e x} & \text { exhaust mass flow rate } & \rho_{a} & \text { ambient air density } \\ \dot{Q} & \text { total heat release rate } & \rho_{L} & \text { smoke layer density } \\ \dot{Q}_{C} & \text { convective heat release rate } & \chi_{R} & \text { radiative fraction } \\ \dot{Q}_{c o n d} & \text { heat loss by conduction at walls } & & \end{array}$




\section{INTRODUCTION}

Recently, the French regulation code relating to smoke control system design of Public Buildings (Établissement Recevant du Public or ERP in French) has been revised [1]. The main change is that from now, "smoke control engineering" can be use to assess performance of a smoke control system employed as an alternative to prescriptive rules. This partial opening to Fire Safety Engineering (FSE) methods forms a first step towards a global performance-based regulation code in France. In the same time, some of the prescriptive rules have been amended. One noticeable change is that the prescriptive mechanical exhaust flow rate has been upgraded from $1 \mathrm{~m}^{3} / \mathrm{s}$ to $3 \mathrm{~m}^{3} / \mathrm{s}$ for each $100 \mathrm{~m}^{2}$ of floor area.

These two main changes have quickly led several building owners to ask CSTB to perform smoke control design studies based on FSE methods. It is important to point out that all the buildings presented in those first studies involved some very large volumes. Indeed, the new regulatory framework has caused some difficulties for large volumes buildings:

- the prescriptive rules give no solution for natural ventilation system when the height under ceiling is above $15 \mathrm{~m}$; this then leads to use a mechanical ventilation system;

- the new prescriptive rules for mechanical exhaust flow rate lead to no costacceptable mechanical solution as soon as floor area of a space is in excess of a certain level, say, $4000 \mathrm{~m}^{2}$ (a high electrical power is need to meet prescriptive rules).

The aim of this paper is to present a comparison of the results obtained with several fire model on a large volume smoke control case study. We used for our comparison a simple hot layer model (detailed in this paper), a mono-volume 2-layers model (FISBA, developed at CSTB) and a field model (FDS, developed at the National Institute of Standards and Technology, USA). Three configurations are studied on one sole fire scenario: one configuration with no exhaust and two configurations with different mechanical exhaust flow rates (corresponding to the old and new prescriptive requirements).

\section{MODELLING TOOLS}

\section{Simple Hot Layer Model}

Our simple hot layer model is based upon the assumption of uniform smoke layer properties (temperature and thickness) that change with time according to the competition between smoke layer filling by the fire plume and smoke layer clearing by exhaust fans. This hot layer model, detailed below, is close to the one presented by Cox in [2].

At a given time, the plume mass flow rate injected into the smoke layer at layer height $H_{L}=H-e_{L}$ is calculated using McCaffrey formula [3]:

$\dot{m}_{P}=C(i) \dot{Q} A^{E(i)}$

where $A=H_{L} / \dot{Q}^{0.4}$ and $C, E$ and $i$ functions of $A$ as shown in the Table 1. 
Table 1. Plume entrainment constants.

\begin{tabular}{|llll|}
\hline$A<0.08$ & $i=1$ & $C(1)=0.011$ & $E(1)=0.566$ \\
\hline$A>0.08$ & $i=2$ & $C(2)=0.026$ & $E(2)=0.909$ \\
\hline$A>0.20$ & $i=3$ & $C(3)=0.127$ & $E(3)=1.895$ \\
\hline
\end{tabular}

Convective heat release rate injected in the smoke layer is given assuming that combustion occurs below the layer height:

$\dot{Q}_{C}=\left(1-\chi_{R}\right) \dot{Q}$

Heat loss by mechanical exhaustion is given by:

$\dot{Q}_{e X}=\dot{m}_{e X} C_{P}\left(T_{L}-T_{a}\right)$

Heat loss by heat transfer at walls is given assuming isothermal walls:

$\dot{Q}_{\text {cond }}=h\left(S_{\text {ceiling }}+2(L+w) e_{L}\right)\left(T_{L}-T_{a}\right)$

Smoke layer temperature is approximated from mass and energy balance assuming that radiation can be neglected:

$T_{L}=\frac{\int_{0}^{t}\left(\dot{Q}_{C}-\dot{Q}_{e x}-\dot{Q}_{\text {cond }}\right) d t}{C_{V} \int_{0}^{t}\left(\dot{m}_{P}-\dot{m}_{e x}\right) d t}+T_{a}$

Smoke layer density is given using the incompressible perfect gas law:

$\rho_{L}=\frac{\rho_{a} T_{a}}{T_{L}}$

The exhaust mass flow rate is given by:

$\dot{m}_{e x}=\rho_{L} \dot{V}_{e x}$

Smoke layer thickness is deduced with:

$e_{L}=\frac{V_{L}}{S_{\text {ceiling }}}=\frac{1}{S_{\text {ceiling }}} \int_{0}^{t} \frac{1}{\rho_{L}}\left(\dot{m}_{P}-\dot{m}_{e X}\right) d t$ 


\section{Two-Zone Model}

FISBA (Feu et Incendie Simulés dans un Bâtiment) is a mono-volume 2-zone model developed at CSTB. In the volume, lower and upper layers, flame and plume zones are described using engineering correlations and differential equations derived from conservation of mass, energy and species. The model predicts gas zones temperatures, interface height, mass fluxes through openings, pressure inside the volume, heat fluxes, temperatures profile in the walls, etc. Radiation is taken into account. Ventilation is taken into account, either natural (vertical and/or horizontal openings, building leakages) and/or mechanical (fans and ducts). Combustion in upper layer can be considered. The chemical species considered are unburned fuel, $\mathrm{O}_{2}, \mathrm{CO}_{2}$. Concentration of $\mathrm{CO}$ can be predicted if the source term is given its production rate. Options exist concerning entrainment rate and convective thermal transfer. Gas entrainment through openings is also considered. One will find details of this model in [4].

\section{Field Model}

FDS (Fire Dynamics Simulator) is a field model developed at NIST (National Institute of Standards and Technology), USA. The model solves on a three-dimensional, rectilinear, multi-block calculation grid the low Mach number approximation to the Navier-Stokes equations describing conservation of mass, momentum, energy and species. Turbulence is modelled with Large Eddy Simulation. Fire involves a mixture fraction based combustion model. Radiation is modelled using a grey gas approximation. Conduction through walls is taken into account. The model predicts local values of temperature, flow speed, pressure field, species concentrations, heat fluxes, etc.

FDS is today widely used in the international fire research community. One will find full details of the model in [5].

\section{LARGE VOLUME CASE STUDY EXAMPLE}

\section{Building Description}

The building we use for our example is under construction in Angoulême, France, and owned by COMAGA (Communauté d'Agglomération du Grand Angoulême). This building is designed to host several activities like expositions, concerts or sport events.

In the framework of the present paper, we are focusing on the main hall of the building. Fig. 1 below gives a view of the hall geometry. This hall has a ground area of around $5000 \mathrm{~m}^{2}$ and a height under ceiling of around $19 \mathrm{~m}$. At the east side of this hall, some stepped rows of seats are set up from floor to $5 \mathrm{~m}$ high and from $8 \mathrm{~m}$ high to $11 \mathrm{~m}$ high. A technical mesh is placed at $14 \mathrm{~m}$ high. 


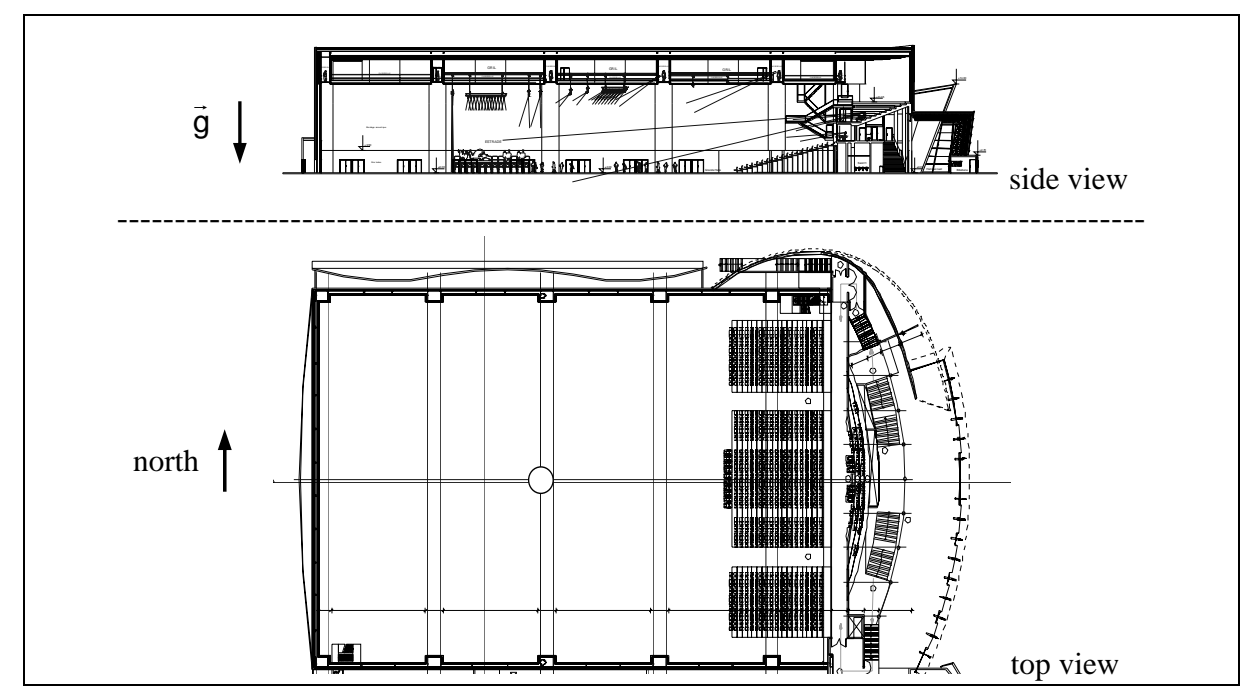

Fig. 1. Main hall geometry.

\section{Smoke Control System Configurations}

Two mechanical exhaust configurations are studied:

- $\quad 10$ exhaust fans of $20000 \mathrm{~m}^{3} / \mathrm{h}$ each (total $56 \mathrm{~m}^{3} / \mathrm{s}$, old regulation requirements);

- $\quad 30$ exhaust fans of $20000 \mathrm{~m}^{3} / \mathrm{h}$ each (total $167 \mathrm{~m}^{3} / \mathrm{s}$, new regulation requirements).

For these two exhaust configurations, a total of 10 double-doors (3 set up on west side of the hall and 7 set up on north side) are connecting the hall volume directly to the outside at ground level, giving a total air supply area of around $75 \mathrm{~m}^{2}$.

\section{Fire Scenario}

Given the various activities that can be hosted in the building, several fire scenarios have been studied with maximum Heat Release Rate (HRR) ranging from 5 MW to more than $50 \mathrm{MW}$. In the framework of this paper, we are focusing on a single fire scenario: we consider a fire of a block of four wood furniture kiosks (total square area is $36 \mathrm{~m}^{2}$ ) in an exposition hall configuration. The HRR of this scenario is given in Fig. 2 below.

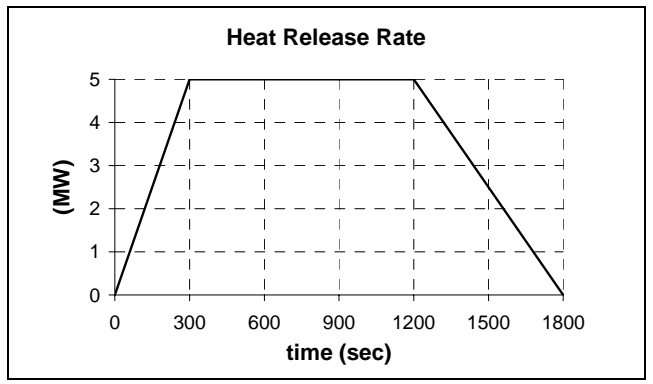

Fig. 2. Fire scenario HRR as function of time. 


\section{Safety Objectives, Safety Criteria and Regulatory Smoke Representation}

The French regulation code [1] states that the main objective of smoke control system is to exhaust, at the beginning of a fire, parts of smoke and combustion gas in order to maintain the escape paths useable while people are evacuating. Smoke control system may also contribute to limit fire propagation and to help fire fighters intervention. Safety criteria used to assess smoke control performance are also found in the regulation code: for example, evacuation routes are considered as useable when the smoke-free height remains sufficient and the heat flux received by people is sufferable.

As prescriptive-based design and performance-based design coexist in the regulation, there is a need to preserve equivalency between those two approaches. Therefore, while performing a FSE study with today's sophisticated models, one has to question what a sufficient smoke-free height is.

The "regulatory smoke-free height" comes from the classical zone representation of a quiet and stratified smoke layer and corresponds to the location of the interface between the hot, smoke-laden upper layer and the cooler lower layer in a burning compartment (see [6]). Relatively simple fire models, like our hot layer model or our two-zone model FISBA, compute this quantity directly, along with the average temperature of the upper layer. In a field model like FDS, there are not two distinct zones, but rather a continuous profile of temperature. There are several methods that have been developed to estimate smoke layer height and average temperatures from a continuous vertical profile of temperature (see [7]). The method chosen by NIST is as follows (see [5]):

For a given vertical temperature profile, the lower layer temperature $T_{b}$ is set to be the temperature in the one sole lowest grid cell near to the floor. Then, the following two integral quantities are used to compute $H_{L}$ :

$$
\begin{gathered}
I_{1}=\int_{0}^{H} T d z=\left(H-H_{L}\right) T_{L}+H_{L} T_{b} \\
I_{2}=\int_{0}^{H} \frac{1}{T} d z=\frac{\left(H-H_{L}\right)}{T_{L}}+\frac{H_{L}}{T_{b}}
\end{gathered}
$$

Equation 9 describes a mathematical averaging procedure set to retain the same mean temperature but has no physical meanings. Equation 10 is a requirement for mass equivalency.

$H_{L}$ is then defined via:

$H_{L}=\frac{T_{b}\left(I_{1} I_{2}-H^{2}\right)}{I_{1}+I_{2} T_{b}^{2}-2 T_{b} H}$

$T_{L}$ is defined via: 
$T_{L}=\frac{1}{H-H_{L}} \int_{H_{L}}^{H} T d z$

Fig. 3 below shows the result of this method applied on a temperature profile obtained from one of our FDS calculation. Assuming that the two-layers profile corresponds to the regulatory smoke representation and the FDS profile corresponds to a real profile, one can note the difference between the "regulatory smoke-free height" which here is around 11 meters and the "effective totally smoke-free height" which in fact appears to be around 6 meters.

Throughout the study, the main safety criteria used for smoke-control system design is as follows: during the evacuation time, the "regulatory smoke-free height" must be maintained at upper than $13 \mathrm{~m}$ ( $2 \mathrm{~m}$ higher than the upper seats).

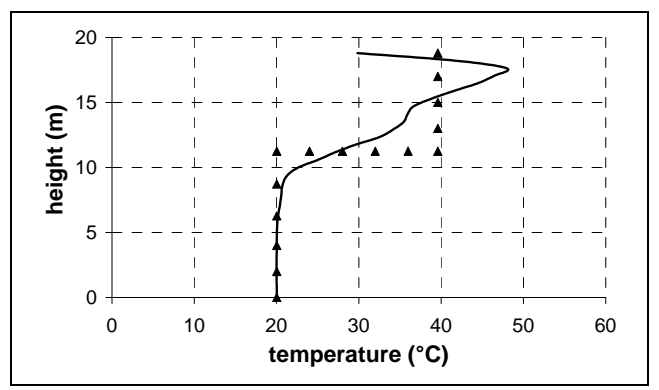

Fig. 3. ^ : Two-layer temperature profile; -: FDS profile.

\section{SIMULATIONS RESULTS COMPARISON}

\section{Simulations Parameters}

In order to simplify comparison between the different configurations and to highlight the different phenomena reproduced by the models, the same parameters and boundary conditions are used for the three models. Radiative fraction of HRR inside the combustion zone is set to $35 \%$. Initial temperature inside the hall is the same as outside temperature and equals $20^{\circ} \mathrm{C}$. There is no wind. For the present comparisons, walls are considered as isothermal (their temperature remains constant and equals $20^{\circ} \mathrm{C}$ during the whole calculation). It is assumed that all the doors are open and all exhaust fans are turned on as soon as fire starts.

In FDS calculations, a wood stoichiometry is used for the combustion reaction. Other parameters are set to their default value. A multi-blocks calculation grid of cubic cells is used to represent the whole geometry of the hall. Mesh sizes are $30 \mathrm{~cm}$ in the fire block, $45 \mathrm{~cm}$ in the four blocks surrounding it and $60 \mathrm{~cm}$ in others. Total cell number is around 700000. This mesh resolution has been found acceptable after refinements from a coarser mesh to a finer mesh (down to $15 \mathrm{~cm}$ mesh size) in the fire plume zone.

\section{Without Exhaust Configuration}

Fig. 4 and Fig. 5 show the results obtained on a configuration without exhaust with the three models. 
Results are very similar between the three models. The initial time decay observed between FDS and the zone models mainly comes from the smoke movement reproduced by field modelling: smoke needs around 3 minutes to form a layer below the whole ceiling surface.

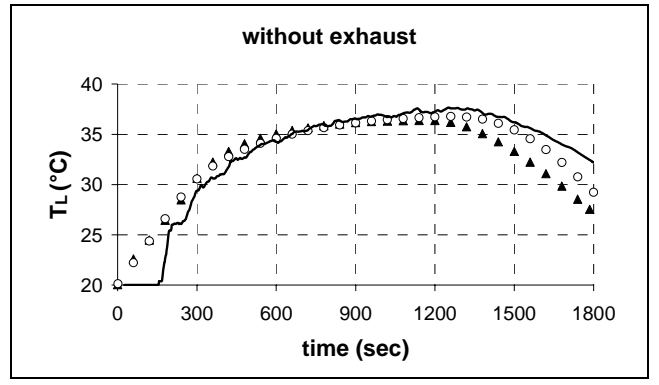

Fig. 4. Smoke layer temperature, without exhaust configuration

( $\mathbf{\Lambda}$ : simple model; $\circ$ : FISBA; -: FDS).

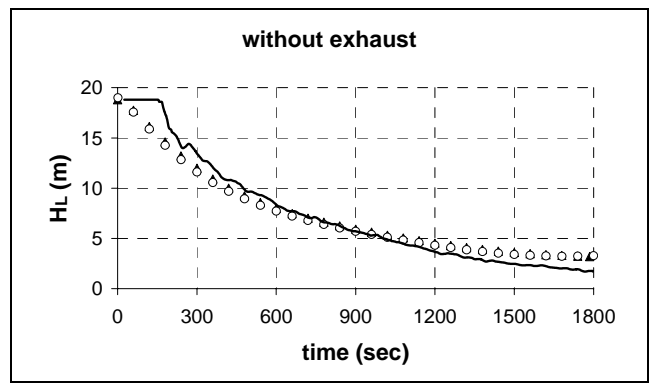

Fig. 5. Smoke layer height, without exhaust configuration

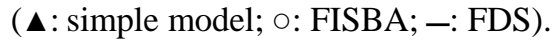

\section{Mechanical Exhaust Configurations}

Fig. 6 to Fig. 9 show the results obtained on the two mechanical exhaust configurations with the three models.

On the configuration with the lowest exhaust volume flow rate $\left(56 \mathrm{~m}^{3} / \mathrm{s}\right)$, there is a very good agreement between the three models. On the configuration with the higher exhaust volume flow rate $\left(167 \mathrm{~m}^{3} / \mathrm{s}\right)$, we can see a clear discrepancy between FDS and the two zone models: FDS's prediction of smoke layer properties with time strongly fluctuates and gives a lower value of smoke layer height. 


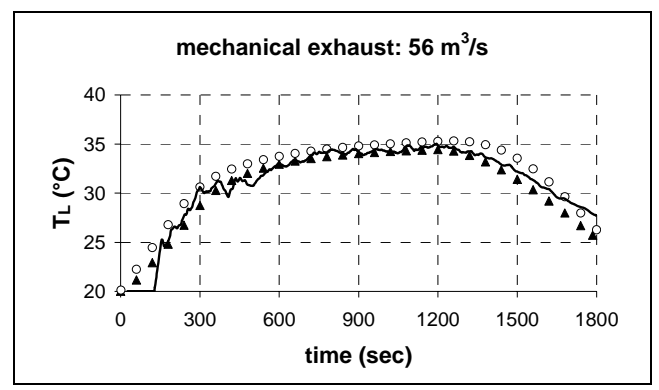

Fig. 6. Smoke layer temperature, $56 \mathrm{~m}^{3} / \mathrm{s}$ exhaust rate configuration ( $\mathbf{\Lambda}$ : simple model; $\circ$ : FISBA; -: FDS).

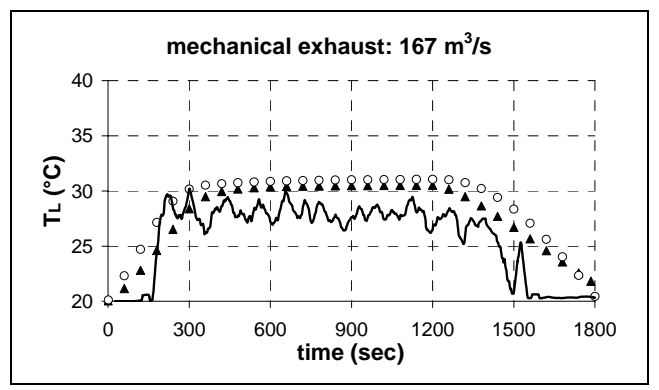

Fig. 7. Smoke layer temperature, $167 \mathrm{~m}^{3} / \mathrm{s}$ exhaust rate configuration ( $\mathbf{\Lambda}$ : simple model; $\circ$ : FISBA; -: FDS).

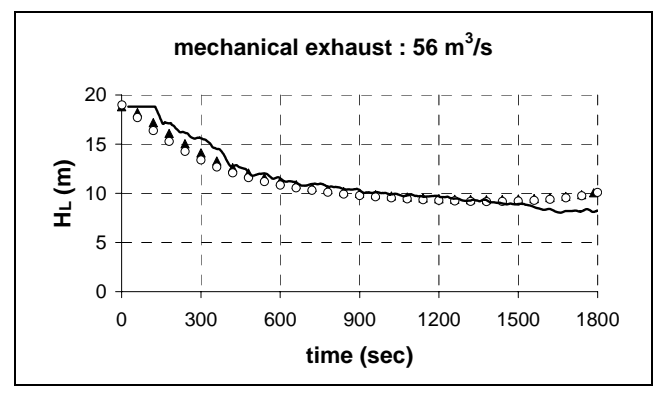

Fig. 8. Smoke layer height, $56 \mathrm{~m}^{3} / \mathrm{s}$ exhaust rate configuration ( $\wedge$ : simple model; ○: FISBA; -: FDS).

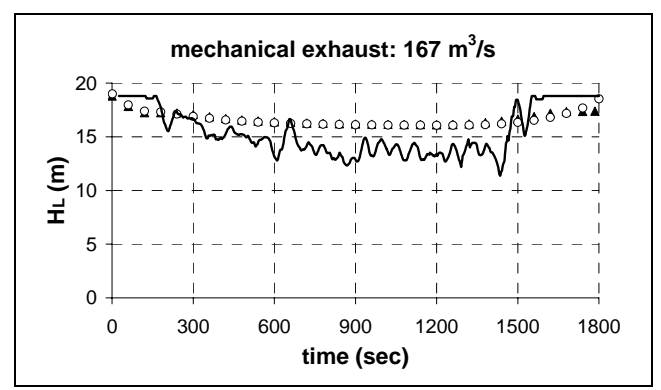

Fig. 9. Smoke layer height, $167 \mathrm{~m}^{3} / \mathrm{s}$ exhaust rate configuration ( $\mathbf{\wedge}$ : simple model; $\circ$ : FISBA; -: FDS). 


\section{Discussion}

The above comparisons show that for situations with no or low exhaust flow rate, simple or more sophisticated zone models give results similar to those obtained with a field model like FDS. For situation with high exhaust flow rate, discrepancy between zone models and field model increases.

One have to note that when analysing the results with the plugholing criteria proposed by Curtat in [8], we find that plugholing can occur only in the very first minutes of the simulations and therefore does not explain the different results obtained.

Fig. 10 reproduces a smoke representation obtained with FDS for the two mechanical exhaust 15 minutes after the beginning of the fire. When the exhaust rate is low, smoke layer is quiet and stratified while for higher exhaust rate, plume and smoke layer appear to be strongly disturbed and smoke exists at floor level.

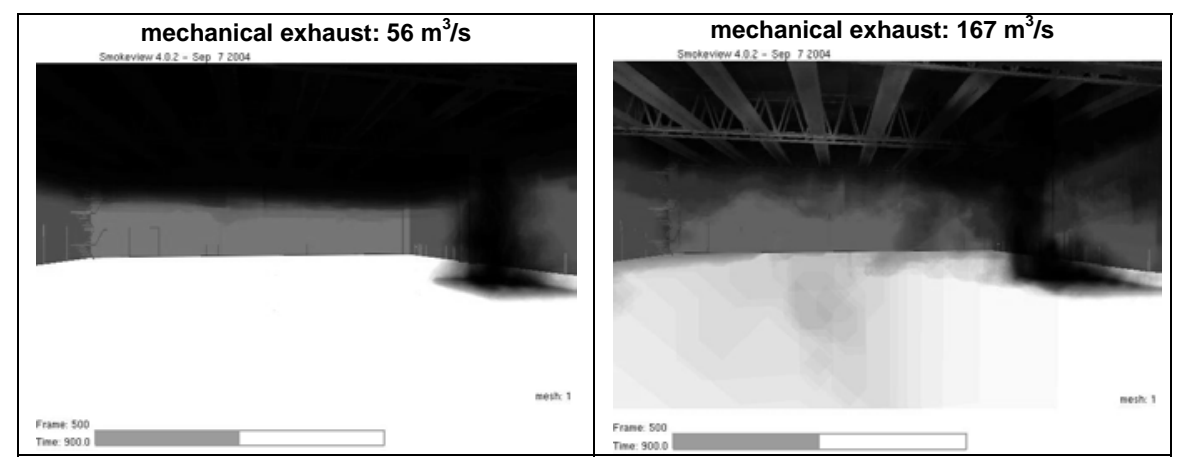

Fig. 10. View of smoke at $t=15$ minutes for the two mechanical exhaust configurations.

The discrepancy between the models is mainly explained by the strong fluid movements that occur inside the volume for high exhaust flow rate. Those strong fluid movements are reproduced with field modelling, whereas they are not taken into account with zone modelling. One can note at least three phenomena occurring at high exhaust rate when the results obtained with FDS are analysed in details. First, as the fire seat is located nearby one of the doors, the incoming fresh air flow greatly disturbs the plume and may lead to a greater plume entrainment. Second, the air supply through the doors also disturbs the smoke layer, causing detrainment of smoke from the smoke layer to the ground. Third, the asymmetric location of both doors and fire seat leads to a strong rotation of the smoke layer; this conducts to an accumulation of smoke in the corners of the volume and also may lead to greater turbulence at the interface between smoke layer and cold layer (therefore greater are the exchanges between the two layers).

These phenomena have already been experimentally observed. For example, rotation of smoke layer due to asymmetric location of fire seat has been highlighted in [9]. Some comparison of fire models on large volume fire experiments have already been done (see for example [10]). One can find in literature several fire experiments in large volume (see for example [11]). In order to test the accuracy of FDS, we are currently performing a bibliographic research to select experimental data set which could present situations similar to those studied in the present paper. 
The discrepancy of the results observed has a non-negligible impact on smoke control system design. Indeed, simple model and FISBA results show that smoke layer height stay upper than the design safety criteria $(13 \mathrm{~m})$ during the whole duration of fire for the $167 \mathrm{~m}^{3} / \mathrm{s}$ mechanical exhaust configuration while FDS results show that none of the configurations studied satisfies the criteria after around 10 minutes of fire.

\section{CONCLUSION}

This paper confirms the interest of a practical use of zone modelling in the design process of smoke control system. Their light demand of computer resources allows one to use zone models for screening a large number of configurations. The feasibility of the use of field modelling for large volume smoke control design according to criteria defined in the French regulation has been demonstrated. In the design process, field modelling appears to be a complementary tool of zone modelling, in particular for situations where one might find discrepancy between the two approaches. Further research is needed in order to determine those situations, with regards to buildings dimensions, fire HRR and exhaust rates.

This paper underlines the potential benefits of field modelling for a global fire safety analysis in large volume. Indeed, from a global fire safety analysis point of view, the local values given by a field model like FDS may give a better picture of what could happen in reality. For example, the fact that one finds smoke well below the "regulatory smoke-free height" used for smoke control system design clearly highlights the need to pay attention to the other procedures and means contributing to safer egress and easier fire fighters intervention (that are, among others, fire prevention measures, conditions of people evacuation, organizational conditions of the first safety measures undertaken at the very beginnings of the fire, etc.).

\section{REFERENCES}

[1] “Arrêté du 22 Mars 2004 portant approbation de dispositions complétant et modifiant le règlement de sécurité contre les risques d'incendie et de panique dans les établissements recevant du public" Ministère de l'intérieur, de la sécurité intérieure et des libertés locales, France, 2004.

[2] Cox, G., "Compartment Fire Modeling," Combustion Fundamentals of Fire, Chapter 6, Academic Press, pp. 329-404, 1995.

[3] McCaffrey, B.J., "Purely Buoyant Diffusion Flames," NBS report - NBSIR n $79-1910,1979$.

[4] Curtat, M., "Modélisation du feu de local - Contribution du CSTB à l'action FIS : le logiciel FISBA (Feu et Incendie Simulés dans un Bâtiment),” Revue générale de Thermique (now International Journal of Thermal Science), tome $27 \mathrm{n}^{\circ}: 315-316,1988$.

[5] McGrattan, K.B., "Fire Dynamics Simulator (version 4), Technical Reference Guide,” NIST special publication 1018, National Institute of Standards and Technology, pp. 94, 2004.

[6] Bodart, X., "Analyse de sous procédures réglementaires de quantification des surfaces utiles d'évacuation de fumées d'incendie en ventilation naturelle," CSTB study report, p. 194, 1989. 
[7] He, Y.P., Fernando, A., and Luo, M.C., "Determination of Interface Height from Measured Parameter Profile in Enclosure Fire Experiment,” Fire Safety Journal, 31, pp. 19-38, 1998.

[8] Curtat, M., "Traité de Physique du bâtiment; Tome 3: Physique du feu pour l'ingénieur,” CSTB - ISBN 2-86891-305-9, pp. 692, 2001.

[9] Bodart, X., Curtat, M., Blay, D., Tuhault, J.L., and Lebotlan, Y., "Study of Fanpowered Extraction of Smoke in a Room Where a Fire Develops: Full-scale Experiments and Computer Simulations Using a Zone Model and a CFD Model," Revue Générale de Thermique (now International Journal of Thermal Science), 36, pp. 372-397, 1997.

[10] Dey, M.K., Hamins, A., and Miles, S., "International Collaborative Project to Evaluate Fire Models for Nuclear Power Plant Applications: Summary of $5^{\text {th }}$ meeting,” NISTIR 6986, National Institute of Standards and Technology, pp. 72, 2003.

[11] Deaves, D.M., and Haighton, A.P., “Zone Model Validation Database,” WS Atkins Consultant Limited, report ${ }^{\circ}$ AM4065-R1, IMC Research Programme, pp. 42, 2000. 